\title{
AN EXAMINATION OF THE PROPERTIES OF SSC PHASE II R\&D STRANDS
}

\author{
P.J. Lee and D.C. Larbalestier*, \\ Applied Superconductivity Center, \\ University of WI-Madison, Madison WI 53706
}

\begin{abstract}
An important part of the SSC Phase I and II strand $R \& D$ programs was an extensive sampling scheme that covered the entire fabrication process of the strand. Samples were sent to the UW where complete microstructural and physical property analyses could be performed. In addition, sufficient extruded pre-heat treatment multifilamentary material was provided to the UW so that parallel processing to strand could be performed. In Phase I material it was found that the 2 vol.\% $\mathrm{Nb}$ diffusion barrier thickness was insufficient to prevent extrinsic limitation of $\mathrm{J}_{\mathrm{c}^{*}}$ This contrasted with the Phase II strand which incorporated $4 \%$ barriers and showed intrinsic behavior. The intrinsic nature of the Phase II conductor has made it possible to probe the basic microstructure property relationships of the strand and provide insight into improvements in future processing.
\end{abstract}

\section{INTRODUCTION}

A reproducible, predictable conductor with a good safety margin over the SSC specification is a vital requirement for the success of the SSC. Since it was always recognized that high $\mathrm{J}_{\mathrm{c}}$ and fine filament diameter were of great technical and economic importance for the SSC design, these parameters were emphasized in the early $R \& D$ studies. These resulted in the $6 \mu \mathrm{m} / 2750 \mathrm{~A} / \mathrm{mm}^{2}$ (5T) choices which form the basis of the present SSC conductor specification. From an R\&D point of view, this $\mathrm{J}_{\mathrm{c}}$ specification had a margin of $\sim 1000 \mathrm{~A} / \mathrm{mm}^{2}$ below the best large filament conductors (Figure 1). This was thought to be sufficient to guarantee the desired properties in production-scale cables. However, recognizing that many factors of the large scale production scale-up of the SSC conductor were unproven, there have been two major $R \& D$ exercises to test the industrial scale-up of the SSC conductors. In the Phase I exercise of 1988-1989, IGC, OST, and Supercon made $6 \mu \mathrm{m}$ and $9 \mu \mathrm{m}$ diameter filament inner conductors with $\mathrm{Nb}$ barrier thicknesses which were $1 \%$ and $2 \%$ of the filament crosssectional areas. $\mathrm{J}_{\mathrm{c}}$ values did not reach $\mathrm{SSC}$ specifications and there was clear evidence in the filament irregularity, the nvalues and the exposed surface of the filaments that the barrier was too thin to protect the $\mathrm{Nb}-\mathrm{Ti}$, particularly in the $6 \mu \mathrm{m}$ composites. Thus these composites were extrinsically limited.([1]) A $15 \mu \mathrm{m}$ filament Fermilab quadrupole conductor having a $2 \%$ barrier was processed at the same time: its barrier remained fully intact and its best $\mathrm{J}_{c}$ exceeded 3200 $\mathrm{A} / \mathrm{mm}^{2}$ (5T).

Research supported by SSCL and by the US Dept. of Energy, Division of High Energy Physics, grant DE-ACO2-82ER4007 Manuscript received August 24, 1992.

*Also The Department of Materials Science and Engineering.

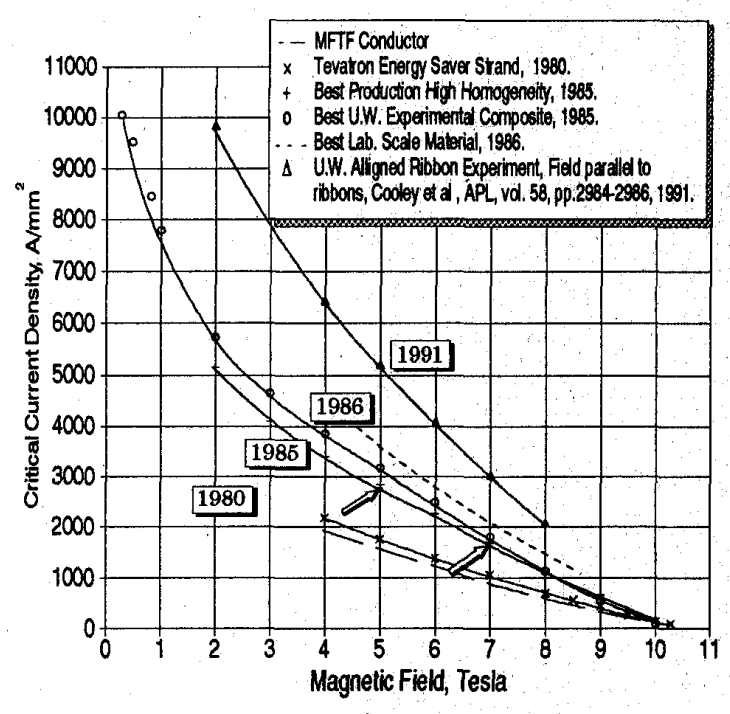

Figure 1. The increasing $\mathrm{J}_{\mathrm{c}}(4.2 \mathrm{~K})$ of $\mathrm{Nb}$-Ti based superconducting strand. Arrows indicate SSC strand specifications.

These lessons strongly guided the Phase II R\&D exercise. A $4 \%$ barrier was specified for these billets in order to ensure that the composites had a greater margin of safety against barrier breakdown. At the time of the specification there was little experience with such thick barriers and some concen that they would be difficult to apply. Thus it was not guaranteed that the Phase II barriers would work, nor was there any basic scientific data to support the rational choice of any particular barrier thickness. A comprehensive sampling scheme was developed at the University of Wisconsin (Table 1) and applied to the R\&D procurement contracts through the SSC conductor advisory committee. The sampling schedule was extremely important as it provided a complete snapshot of high field conductor processing for the SSC without compromising the proprietary nature of the individual wire manufacturers' processing routes. By providing the UW with both the original monofilamentary material and extruded SSC composites, the behavior of each element of the process could be assessed under controlled conditions. The large number of samples provided both an archive for future reference and a source for systematic studies. Although the sampling schedule was not completely adhered to by some of the manufacturers, a clear picture has emerged of the behavior of these composites.

This paper summarizes a detailed characterization of the 
Table 1. Sampling requirements for the Phase II SSC research and development contracts.

1. Samples for Independent Processing

\begin{tabular}{|c|c|}
\hline Nb-Ti alloy stock: & $\begin{array}{l}\text { Partial sections at final anneal (i.e. log size) required for grain size measurement and } \\
\text { homogeneity assessment. } \\
\text { Flash radiographs shall be supplied if available. }\end{array}$ \\
\hline Starting stock: & $\begin{array}{l}\text { Barrier clad monofilament material at } \sim 0.3^{\prime \prime} \text { dia. }(\sim 10 \mathrm{lbs}) \text {. } \\
\text { Extrusion stack stock at extrusion stack size }(\sim 10 \mathrm{lbs}) \text {. }\end{array}$ \\
\hline $\begin{array}{l}\text { Post extrusion } \\
\text { multifilament stock: }\end{array}$ & $\begin{array}{l}\text { (i) The extrusion shall be cut into } 2 \text { pieces of approximately equal length. Two } 1^{\text {" }} \text { long } \\
\text { pieces from the extrusion center shall be retained for microscopic examination. } \\
\text { (ii) A length to be determined ( } ~-50 \mathrm{lbs}) \text { shall be retained at extrusion size for separate } \\
\text { processing. }\end{array}$ \\
\hline Rod process stock: & $\sim 30$ lbs shall be held at $\sim 1 "$ diameter $( \pm .05 ")$ for separate processing. \\
\hline
\end{tabular}

Note: all multifilament samples shall be cut from the center section of the billet.

2. Samples from Material Processed by the Manufacturer

Heat treatment sizes: $\quad$ 6" long samples shall be retained before and after each heat treatment.

Close to final size: $\quad 10 \mathrm{~m}$ of wire shall be retained at $\sim 0.1$ " dia.

Phase II R\&D billets produced by IGC, OST and Supercon, samples of which were supplied to the UW. In order not to disclose proprietary information, the samples have been identified as from manufacturers A-C (not necessarily respectively) and alloy suppliers $\mathrm{X}$ and $\mathrm{Y}$.

\section{EXPERIMENTAL DESIGN}

A standard evaluation was performed on each SSC billet supplied under the SSC Phase II R\&D contract. Each billet was processed using the three heat treatment schedules shown in Figure 2. The heat treatments represent both the non-aggressive heat treatments (i.e. low temperature and time) that were preferred before sufficient diffusion barriers were used and an aggressive heat treatment $(3 \times 80 \mathrm{hr} / 420 \mathrm{C})$ designed to produce a large amount of precipitate. In addition to the SSC-Inner billets, SSC monofilament rods were assembled into 61filament test composites at the UW. These test billets were processed at the UW and given the same heat treatments as the SSC billets. The standard schedules for the UW-61 stacks are shown in Figure 3, where the total strain is calculated assuming

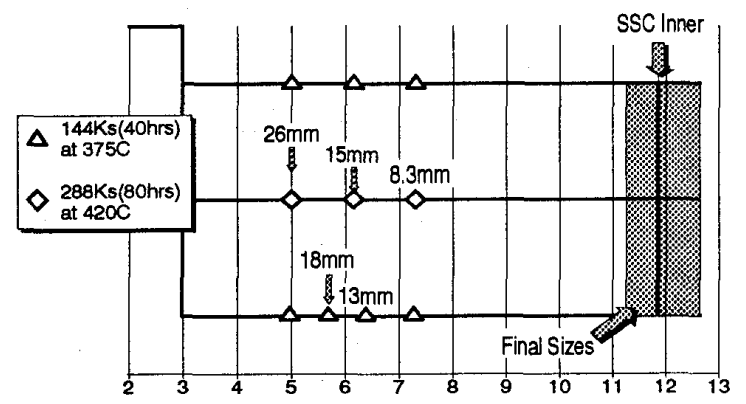

True Strain Measured from the Multifilament Extrusion Stack Size

Figure 2 The three standard heat treatments applied to all the SSC Phase II multifilamentary R\&D Billets. that the monofilament was cold worked from its initial diameter of $229 \mathrm{~mm}$ without intermediate anneal (an intermediate anneal would effectively reduce these values([2])). Performing the wire drawing at the UW allowed us to monitor the drawability of the strand. The results of the critical current tests on these composites were used to provide a basis for further processing and selection for microstructural evaluation. A complete metallographic analysis was performed on each composite, as well as "sharp bend" and "spring-back" tests where appropriate.

\section{RESULTS}

In general the Phase II material showed very little sausaging (coefficient of variation in cross-sectional area, $\sigma_{\mathfrak{n}-1} / \bar{A}$, of $4-6 \%$ at final wire size) and high n-values ( $>40$ at $5 T$ ), indicating that the properties of these composites can be treated as approaching the intrinsic limit.

\section{A. Physical Properties}

In Table 2 the $\mathrm{J}_{\mathrm{c}}$ behavior of two typical Phase II R\&D

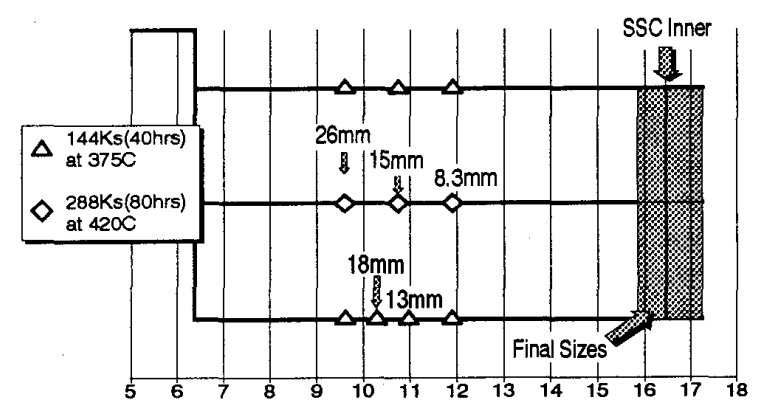

True Strain Measured from the Monofilament Stack Size

Figure 3 The three standard heat treatment processes applied to all the UW-61 filament stacks. 
SSC (Inner) composites are compared. The composites were manufactured by Manufacturer $C$ and Manufacturer $A$ and supplied at $26 \mathrm{~mm}$ diameter to the University of Wisconsin where they were heat treated and drawn under controlled, nominally identical conditions. Both sets of final conductors have quite respectable n-values (typically 50-70 at 5T) for both non-aggressive $\left(40 \mathrm{hr} / 375^{\circ} \mathrm{C}\right)$ and aggressive $\left(80 \mathrm{hr} / 420^{\circ} \mathrm{C}\right)$ heat treatments and are thus not intrinsically limited at the wire diameters of interest. The $J_{c}$ performance, however, is disappointing with only extensive lower temperature (4 to $6 \mathrm{x}$ $40 \mathrm{hr} / 375^{\circ} \mathrm{C}$ ) or aggressive higher temperature heat treatments being successful at obtaining the SSC specifications for $J_{c}$ $\left(2750 \mathrm{~A} / \mathrm{mm}^{2}\right.$ at $5 \mathrm{~T}$ or $1650 \mathrm{~A} / \mathrm{mm}^{2}$ at $\left.\mathrm{TT}\right)$.

The increased barrier thickness (4\% of cross-section), which was introduced after the Phase I R\&D exercise indicated that 1 or $2 \%$ barriers were insufficient, has been very successful in inhibiting the $\mathrm{Cu}-\mathrm{Ti}$ intermetallic reaction. This is illustrated by the consistent increase in $\mathrm{J}_{c}$ which is obtained by increasing the aggression of heat treatment. This contrasts with the Phase I exercise where increasing the aggression of the heat treatment progressively degraded the $J_{c^{*}}$ The effectiveness of the thicker barriers allows for the application of additional heat treatments that can raise the $J_{c}$ to over $3000 \mathrm{~A} / \mathrm{mm}^{2}$ at 5T.([3]) The increase in $J_{c}$ with aggression of HT is similar for both Manufacturer $A$ and Manufacturer $C$ billets. Overall, however, the magnitude of $J_{c}$ for the Manufacturer A composite is typically $\sim 5 \%$ less than for the equivalent Manufacturer $\mathrm{C}$ composite. A known defect of the Manufacturer A composite is that it was stacked with $\mathrm{Nb}$-Ti monofilaments from two different alloy sources (supply " $X$ " and "Y").([4]) A similar billet stacked entirely from the "treeringed" supply "Y" material (Manufacturer A-6) performed even worse. Another significant difference is that the Manufacturer C composite was stacked as a $305 \mathrm{~mm}$ diameter extrusion whereas the Manufacturer A was stacked at $279 \mathrm{~mm}$ diameter. The $J_{c}$ values of the Manufacturer C SSC billets can be compared with those developed in UW-fabricated 61 filament composites made from the same monofilament stock as
Table 3. The $\mathrm{J}_{\mathrm{c}}$ performance of a UW-61 stack made from the same monofilament (C-A) as the SSC-inner strand in Table II.

\begin{tabular}{ccccccc}
\hline \hline $\begin{array}{c}\text { Com- } \\
\text { posite }\end{array}$ & $\begin{array}{c}\text { Heat } \\
\text { Treatment }\end{array}$ & $\begin{array}{c}\text { Field, } \\
\mathbf{T}\end{array}$ & $\begin{array}{c}\text { Peak } \\
\mathbf{J}_{\mathrm{c}}\end{array}$ & $\begin{array}{c}\text { n- } \\
\text { value }\end{array}$ & $\varepsilon_{\mathrm{f}}$ & $\begin{array}{c}\text { Wire } \\
\text { Diam.,mm }\end{array}$ \\
\hline $\mathrm{UW}$ & $3 \times$ & 5 & 2856 & 52 & 4.66 & 0.403 \\
4631 & $40 \mathrm{hrs} /-$ & 5.6 & 2525 & 43 & 4.66 & 0.403 \\
& $375^{\circ} \mathrm{C}$ & 7 & 1771 & - & 4.53 & 0.359 \\
& & 8 & 1232 & - & 4.53 & 0.359 \\
$\mathrm{UW}$ & $3 \times$ & 5 & 3047 & 66 & 5.11 & 0.322 \\
4638 & $80 \mathrm{hrs} /-$ & 5.6 & 2700 & 59 & 5.11 & 0.322 \\
& $420^{\circ} \mathrm{C}$ & 7 & 1827 & 39 & 5.11 & 0.322 \\
& & 8 & 1202 & 18 & 5.11 & 0.322 \\
$\mathrm{UW}$ & $4 \times$ & 5 & 3010 & 67 & 4.42 & 0.454 \\
4641 & $40 \mathrm{hrs} /-$ & 5.6 & 2650 & 59 & 4.42 & 0.454 \\
& $375^{\circ} \mathrm{C}$ & 7 & 1801 & 36 & 4.42 & 0.454 \\
& & 8 & 1200 & 36 & 4.42 & 0.454 \\
\hline \hline
\end{tabular}

the Manufacturer C SSC composite (Table 3). The principal differences between the processing of the SSC composites and the UW 61 filament composite are (i) that the UW composites are assembled and drawn without extrusion, (ii) that the effective strain before the first heat treatment is larger than that for the SSC composites (9.6 vs. 5) and (iii) that the filament size (and thus the barrier thickness) at heat treatment are greater. This leads to a $J_{c}$ which is $~ 300 \mathrm{~A} / \mathrm{mm}^{2}$ higher than the extruded SSC conductor material. This has been typical of our 61 stack composites when compared to industrially extruded composites.

\section{B. Microstructural Evaluation}

In Figure 4 all available volume $\% \alpha$-Ti measurements for Phase II monofilament based UW 61-filament stacks and SSC multifilamentary (samples from Manufacturers $A, B$ and $C$ ) strands are plotted versus the $\mathrm{J}_{\mathrm{c}}$ for that material at a final strain, $\varepsilon_{f}$, of 4.4. As the volume $\%$ of $\alpha$-Ti increases so does the $J_{c}$ The relationship between $J_{c}$ and volume $\% \alpha$-Ti is shown to be

Table 2. $\mathrm{J}_{\mathrm{c}}$ Performance of two Phase II R\&D SSC Composites

\begin{tabular}{|c|c|c|c|c|c|c|c|c|c|c|}
\hline \multirow{2}{*}{$\begin{array}{l}\text { Composite (first } \\
\text { letter denotes } \\
\text { manufacturer). }\end{array}$} & \multirow[t]{2}{*}{ UW ID } & \multicolumn{3}{|c|}{ Heat Treatments } & \multicolumn{4}{|c|}{$\mathrm{J}_{\mathrm{c}}\left(\mathrm{A} / \mathrm{mm}^{2}\right) / \mathrm{n}$-value at four fields } & \multirow{2}{*}{$\begin{array}{l}\text { Final } \\
\text { Strain, } \\
\varepsilon_{\mathrm{f}}\end{array}$} & \multirow{2}{*}{$\begin{array}{l}\text { Wire } \\
\text { Diameter } \\
\text { mm }\end{array}$} \\
\hline & & $\#$ & Time, hrs & Temp. ${ }^{\circ} \mathrm{C}$ & $5 \mathrm{~T}$ & $5.6 \mathrm{~T}$ & $7 \mathrm{~T}$ & $8 T$ & & \\
\hline \multirow[t]{5}{*}{ C-B } & 4331 & 3 & 40 & 375 & $2510 /-$ & $2230 / 63$ & $1590 / 52$ & $1100 / 44$ & 4.64 & 0.81 \\
\hline & 4338 & 3 & 80 & 420 & $2840 / 66$ & $2500 /-$ & $1720 / 76$ & $1130 / 43$ & 4.63 & 0.81 \\
\hline & 4341 & 4 & 40 & 375 & $2620 / 96$ & $2330 / 47$ & $1650 / 49$ & $1120 / 39$ & 4.63 & 0.81 \\
\hline & $4320 \mathrm{~A}$ & 6 & 40 & $375^{*}$ & $3010 / 66$ & $2500 / 59^{\dagger}$ & $1810 / 42$ & $1180 / 42$ & 4.41 & 0.81 \\
\hline & C-B-2 & \multicolumn{3}{|c|}{ As processed at $\mathrm{C}$} & $2690 / 53$ & $2290 / 59$ & $1610 / 51$ & $1080 / 34$ & & \\
\hline \multirow[t]{3}{*}{ A-A-2 } & 5431 & 3 & 40 & 375 & $2440 / 78$ & $2160 / 46$ & $1560 / 66^{\dagger \dagger}$ & $1060 / 38^{t \dagger}$ & 4.62 & 0.81 \\
\hline & 5438 & 3 & 80 & 420 & $2690 / Q$ & $2390 / 76$ & $1650 / 42$ & $1130 / 37$ & 4.87 & 0.73 \\
\hline & 5441 & 4 & 40 & 375 & $2510 / 56$ & $2240 / 62$ & $1590 / 60$ & $1090 / 36^{\mathrm{tt}}$ & 4.87 & 0.73 \\
\hline
\end{tabular}

$\mathrm{J}_{c}$ results in bold face italics reached SSC strand specification at $5 \mathrm{~T}\left(2750 \mathrm{~A} / \mathrm{mm}^{2}\right)$ or $7 \mathrm{~T}\left(1650 \mathrm{~A} / \mathrm{mm}^{2}\right)$. ${ }^{*}=3$ rd $\mathrm{HT}$ was at $350 \mathrm{C}, \mathrm{Q}=$ specimen quenched during testing. $\dagger=\varepsilon_{\mathrm{f}}=4.56$, wire diameter $=0.75 \mathrm{~mm}, \dagger=\varepsilon_{f}=4.86$, wire diameter $=0.73 \mathrm{~mm}, \dagger \dagger=\varepsilon_{\mathrm{f}}=4.63$, wire diameter $=0.81 \mathrm{~mm}$. 
similar for not only the SSC strand and non-extruded 61 filament UW stack but also for our best monofilament. This trend is indicated by the solid line in Figure 4. The high nvalues of these composites are strong evidence that their behavior is in the "intrinsic" limit and therefore these results indicate that these composites behave essentially the same with respect to the same levels of precipitation.

In Figure 5 the precipitation rates under different heat treatments are indicated for the same samples as those used for Figure 4. In this plot a clear separation emerges between SSC multifilamentary strand and the non-extruded UW 61 stacks of SSC monofilament (as well as the "best" monofilament). In all cases, for a given heat treatment, $20-30 \%$ more $\alpha$-Ti is produced in the monofilament and UW monofilament stacks. The clear implication of figures 4 and 5 is that the reduced $J_{c}$ levels found in the SSC strand are primarily due to their reduced amounts of precipitate. Figure 5 also indicates that increased levels of precipitation can be produced by increasing the aggressiveness of the heat treatment.

\section{C. $J_{c}$ vs B Slope}

A VSM (Vibrating Sample Magnetometer) was used to perform $J_{c}$ measurements over a wide range of fields (0.69.0T)3. These results (for the Manufacturer C-B billet with three different heat treatment schedules) are combined in Figure 6 with the calculated gradient $(\Delta J / \Delta B)$ between data points. The three different heat treatment schedules produced different magnitudes of $J_{c}$ in keeping with the different volume

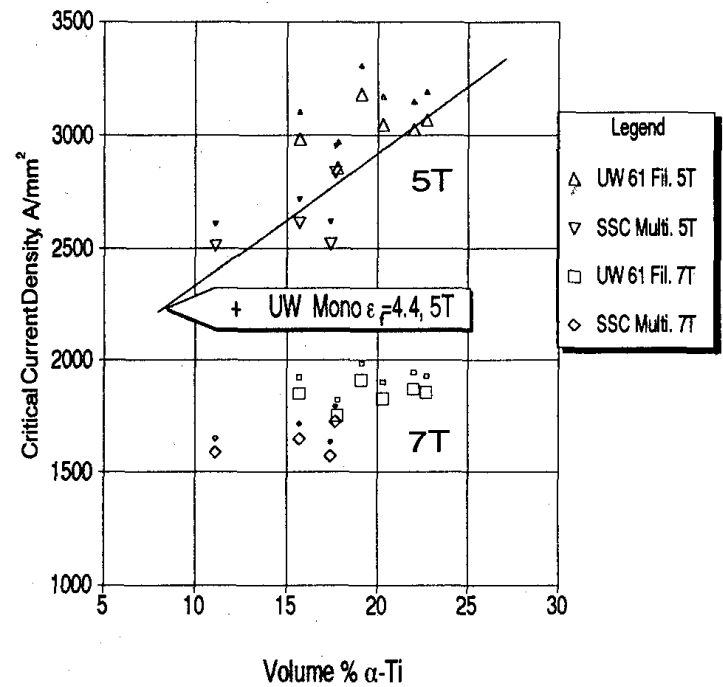

Figure 4 Peak $\mathrm{J}_{\mathrm{c}}$ vs. volume $\% \alpha$-Ti for all Phase II R\&D conductors measured. The small symbols are $\mathrm{Nb}$ $\mathrm{Ti}_{\mathrm{c}}$ values corrected for the $4 \%$ barrier. The superimposed trend is for our best UW monofilament.

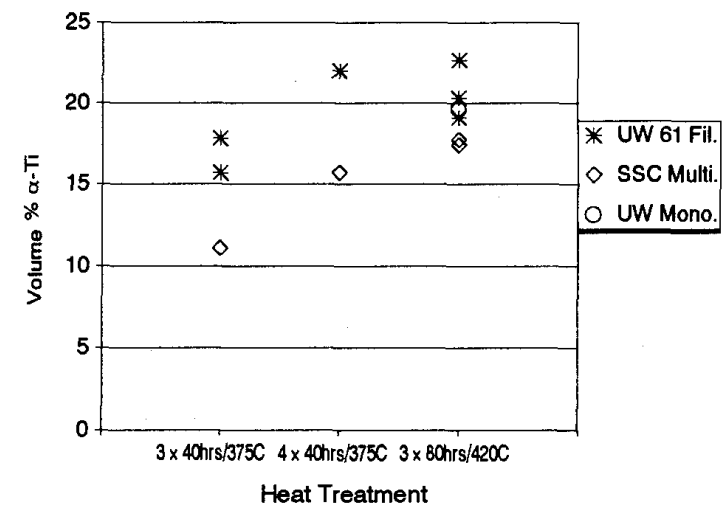

Figure 5 Volume \% $\alpha$-Ti versus heat treatment schedule for both Phase II R\&D SSC strand and UW-61 filament stacks of Phase II R\&D monofilament.

percentages of $\alpha$-Ti; however, for the two strands having identical precipitate size (measured after final heat treatment) the gradient in $J_{c}$ versus field is identical across the entire field range.

The $J_{C} / B$ slopes change with precipitate dimensions; this is illustrated in Figure 7 where $J 5 T / J_{c} 7 T$ is plotted versus strain for a UW-61 stack of Manufacturer A-4-B1 monofilament. The larger precipitates produced by the more aggressive heat treatments result in greater $5 \mathrm{~T} / 7 \mathrm{~T} \mathrm{~J}_{\mathrm{c}}$ ratios. As final strain is increased, the precipitates are reduced in size and spacing, thus resulting in a decrease in 5T/7T $\mathrm{J}_{c}$ slope. In Table 4 the $5 \mathrm{~T} / 7 \mathrm{~T}$ $\mathrm{J}_{\mathrm{c}}$ ratios at a final strain of 4.6 are summarized. The ratios are very reproducible (as illustrated by the low coefficients of variation) for a given type of composite (SSC inner strand or UW stack) and heat treatment. For a given heat treatment the UW-61 stacks have a consistently higher $5 \mathrm{~T} / 7 \mathrm{~T} \mathrm{~J}_{\mathrm{c}}$ ratios. It was found that the Manufacturer $\mathrm{A}$ inner strand that contained the "tree-ringed" supply "Y" alloy had consistently lower 5T/7T J ratios (1-3\% lower for all supply " $Y$ " material and $0.5-2 \%$ for billets using a mix from alloy vendors " $\mathrm{X}$ " and " $\mathrm{Y}$ "). These results suggest that the composites made from supply " $\mathrm{X}$ " alloy have very reproducible precipitate size characteristics for a given heat treatment but the UW-61 filament stacks are producing different precipitate sizes than the SSC-Inner composites. The TEM results indicate an average nominal precipitate diameter of $86 \mathrm{~nm}$ for the SSC inner and $80 \mathrm{~nm}$ for UW 61 stacks given $3 \times 144 \mathrm{Ks}(40 \mathrm{hr}) / 375 \mathrm{C}$ and $168 \mathrm{~nm}$ for SSC inner and $203 \mathrm{~nm}$ for UW 61 stacks given $3 \times 288 \mathrm{Ks}(80 \mathrm{hr}) / 420 \mathrm{C}$. Thus there is a precipitate size difference between similarly processed SSC inner and UW-61 stacks.

The relationship between precipitate size after the final heat treatment and the 5T/7T $\mathrm{J}_{\mathrm{c}}$ ratio is shown in Figure 8, Figure 10. As precipitate size increases, so does the $\mathrm{J}_{c}(5 \mathrm{~T}) / \mathrm{J}_{c}(7 \mathrm{~T})$ ratio. Linear regression fits to the data in Figure 8, Figure 10 indicate 


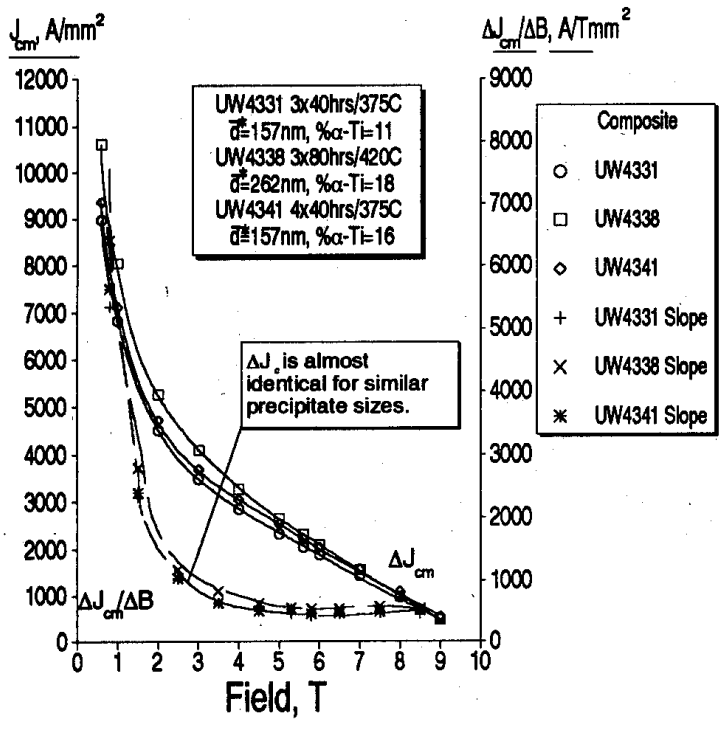

Figure 6 The effect of precipitate size on the $J_{c}$ versus field gradient (magnetization $\mathrm{J}_{\mathrm{c}}$ measurements performed by J. C. McKinnell)

similar gradients for the UW-61 stacks $(\sim 0.0010)$ and the SSC inner strand $(\sim 0.0011)$; however, there is a higher intercept $(+\infty 0.06)$ for the UW-61 stacks, resulting in lower $5 \mathrm{~T} / 7 \mathrm{~T} \mathrm{~J}_{\mathrm{c}}$ ratios for the SSC inner material.

\section{Filament Sausaging}

The degree of filament sausaging was estimated from the variation in filament cross-sectional areas within a sample transverse cross-section. In general there was a linear trend in increasing coefficient of variation $\left(\sigma_{n-1} / \bar{A}\right)$ of filament crosssectional area with increasing true strain after billet stacking.

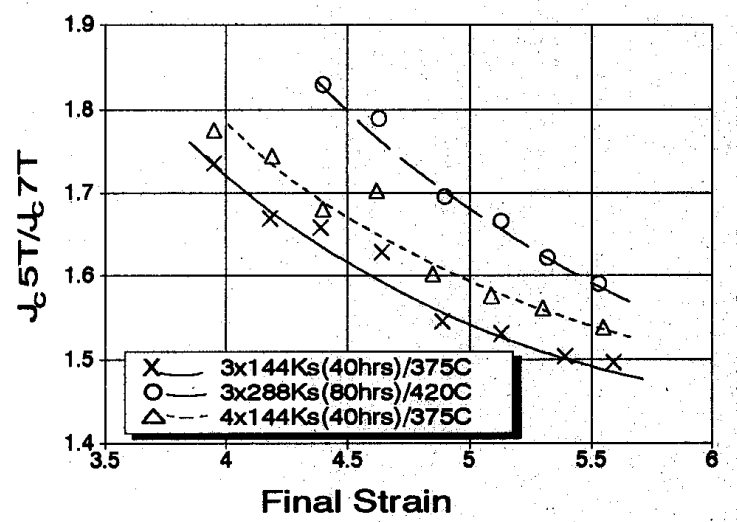

Figure $7 . \mathrm{J}_{c-S \mathrm{~T}} / \mathrm{J}_{\mathrm{c} 7 \mathrm{~T}}$ versus final drawing strain for three UW61 stacks of Manufacturer A B1 monofilament.

This is illustrated in Figure 9 where the coefficient of variation is plotted against total strain for the three standard heat treatments applied to three SSC stacks from manufacturer A. The implication of this result is that the sausaging for this range of heat treatments $(3 \times 40 \mathrm{hr} / 375 \mathrm{C}, 3 \times 80 \mathrm{hr} / 420 \mathrm{C}$ and $4 \times 40 \mathrm{hr} / 375)$ is independent of heat treatment. This is an indication that the 4\% barrier has succeeded in its primary goal of protecting the filaments from embrittling intermetallic formation.

\section{E. Spring-back test and Sharp bend tests}

The wires processed at the UW were not shaved as are those processed by industry. The result is a higher copper to superconductor ratio in our specimens. The additional $\mathrm{Cu}$ in the UW samples tends to reduce the overall modulus of the wire, reducing the springback values. In the case of the sharp bend test, the additional external Cu reduces the strain on the $\mathrm{Nb}-\mathrm{Ti}$ filaments and thus the test results on the UW composites will

Table 4. Summary of $\mathrm{J}_{\mathrm{c}} 5 \mathrm{~T} / \mathrm{J}_{\mathrm{c}} 7 \mathrm{~T}$ values at $\varepsilon_{\mathrm{f}}=4.6$

\begin{tabular}{|c|c|c|c|c|c|c|c|c|c|}
\hline \multirow{4}{*}{ HT } & \multirow{4}{*}{ Statistics } & \multicolumn{8}{|c|}{$\bar{J} \mathrm{~J} 5 \mathrm{~T} / \mathrm{J}_{\mathrm{c}} T \mathrm{~T}$} \\
\hline & & \multicolumn{2}{|c|}{ All Strands } & \multirow{3}{*}{$\begin{array}{l}\text { UW-61 } \\
\text { Stack }\end{array}$} & \multicolumn{5}{|c|}{ SSC Composites (Inner) 0.032"diam. } \\
\hline & & & Except & & \multirow[t]{2}{*}{$\overline{\text { All }}$} & \multirow{2}{*}{$\begin{array}{l}\text { Except } \\
\text { Mix }^{*}\end{array}$} & \multicolumn{3}{|c|}{ Manufacturer } \\
\hline & & & & & & & C & $\mathbf{A}$ & $\mathrm{B}$ \\
\hline \multirow{3}{*}{$\begin{array}{l}3 x \\
40 \mathrm{hrs} \\
\text { at } \\
375 \mathrm{C} \\
\end{array}$} & Avg. & 1.604 & 1.615 & 1.638 & 1.592 & 1.603 & 1.580 & 1.571 & 1.608 \\
\hline & $\sigma_{n-1}$ & 0.028 & 0.021 & 0.011 & 0.022 & 0.014 & 0.001 & 0.018 & 0.006 \\
\hline & $\sigma_{\mathrm{n}-1} / \overline{\mathrm{A}}$ & $1.8 \%$ & $1.3 \%$ & $0.66 \%$ & $1.4 \%$ & $0.85 \%$ & $0.1 \%$ & $1.1 \%$ & $0.4 \%$ \\
\hline \multirow{3}{*}{$\begin{array}{l}3 x \\
80 \mathrm{hrs} \\
\text { at } \\
420 \mathrm{C}\end{array}$} & Avg. & 1.699 & 1.706 & 1.764 & 1.659 & 1.676 & 1.653 & 1.664 & 1.684 \\
\hline & $\sigma_{\mathrm{n}-1}$ & 0.045 & 0.045 & 0.016 & 0.040 & 0.017 & 0.005 & 0.012 & 0.013 \\
\hline & $\sigma_{\mathrm{n}-1} / \overline{\mathrm{A}}$ & $2.6 \%$ & $2.6 \%$ & $0.90 \%$ & $2.4 \%$ & $1.0 \%$ & $.33 \%$ & $70 \%$ & $.78 \%$ \\
\hline \multirow{3}{*}{$\begin{array}{l}4 \mathrm{x} \\
40 \mathrm{hrs} \\
\text { at } \\
375 \mathrm{C}\end{array}$} & Avg. & 1.638 & 1.642 & 1.665 & 1.625 & 1.631 & 1.594 & 1.620 & 1.638 \\
\hline & $\sigma_{n-1}$ & 0.030 & 0.029 & 0.027 & 0.026 & 0.023 & 0.007 & 0.017 & 0.008 \\
\hline & $\sigma_{n-1} / \bar{A}$ & $1.8 \%$ & $1.8 \%$ & $1.6 \%$ & $1.6 \%$ & $1.4 \%$ & $.44 \%$ & $1.0 \%$ & $46 \%$ \\
\hline
\end{tabular}

*=some Manufacturer A billets used a mixture of alloys from both suppliers " $X$ " and " $Y$ " in the same multifilamentary stack. 


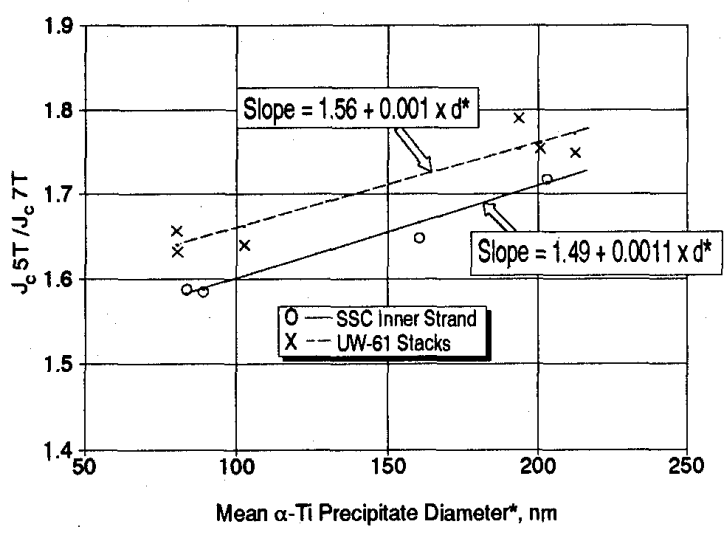

Figure $8 \mathrm{~J} 5 \mathrm{~T} / \mathrm{J}_{\mathrm{c}} T \mathrm{~T}\left(\varepsilon_{\mathrm{f}}=4.6\right)$ versus mean precipitate diameter* after final heat treatment. $*$ : calculated assuming a circular cross-section.

tend to be optimistic. However the UW test results can still be used as a relative guide to performance. The results of the spring-back and sharp bend test results are listed in Table 5 in order of the spring-back degree. All strands passed the SSC Springback specification for Inner conductor $\left(<980^{\circ}\right)$. The variation in spring-back degree is clearly manufacturer, rather than heat treatment, related. A statistical evaluation is given in Table 6. Only one composite (C-B) succeeded in passing the sharp bend test after $420 \mathrm{C}$ heat treatments. The Manufacturer A billets had consistently high spring-back values. Manufacturer $B$ and $C$ conductors varied in the mid-

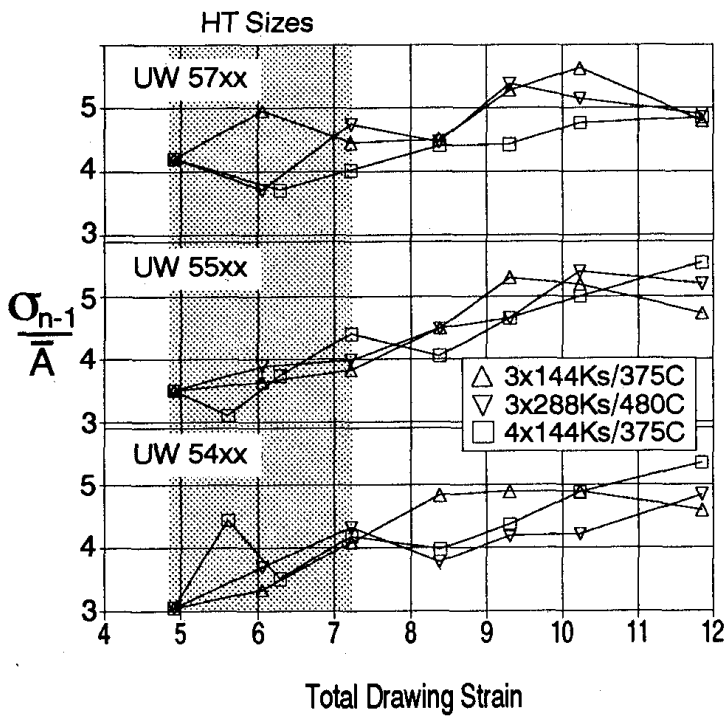

Figure $9 \sigma_{\mathrm{n}-\mathrm{l}} / \overline{\mathrm{A}}$ versus true strain from extrusion stack for three SSC Phase II R\&D Inner stacks from Manufacturer A. range of springback values without a consistent trend with heat treatment or billet number.

\section{F. Alloy Quality}

Only two alloy vendors were used for this study, supply " $X$ " and supply " $Y$ " and only one billet was made entirely of "Y" alloy. The " $Y$ " alloy was in most cases noticeably "treeringed" in transverse cross-section when etched, indicating a considerable degree of chemical inhomogeneity. Billets manufactured using the " $Y$ " "tree-ringed" alloy performed significantly worse than equivalent billets manufactured from supply " $X$ " only alloy (compare Manufacturer A-8 and A-6 with Manufacturer A-7). The supply " $X$ " alloy showed a consistent grain size variation with position, the grain size at the center of the billet was typically $40 \%$ smaller (by lineal intercept) than the outside of the billet (Table 7). Another typical feature of the supply "X" alloy was a tendency to duplex grain sizes, most noticeably towards the outside of the billet.

\section{G. Hardness}

The Vickers Hardness of all the supplied SSC Phase II R\&D post-extrusion material was measured as an indicator of the level of retained cold-work. Filaments were measured at intervals across the billet cross-section in order to check the uniformity across the extrusion. The $\mathrm{H}_{v}$ results for four $76 \mathrm{~mm}\left(3^{\prime \prime}\right)$ post extrusion billets are illustrated in Figure 10. There is no discernable variation in $\mathrm{H}_{v}$ with position and three

Table 5. Spring-back and sharp-bend test results.

\begin{tabular}{|c|c|c|c|c|c|c|}
\hline \multirow[t]{2}{*}{$\begin{array}{l}\text { UW } \\
\text { ID }\end{array}$} & \multicolumn{3}{|c|}{$\begin{array}{l}\text { Heat Treatment } \\
\text { Schedule }\end{array}$} & \multirow[t]{2}{*}{$\begin{array}{l}\text { Billet } \\
\text { ID }^{* *}\end{array}$} & \multirow{2}{*}{$\begin{array}{l}\text { Spring- } \\
\text { back, } \\
\text { degrees }\end{array}$} & \multirow[t]{2}{*}{$\begin{array}{l}\text { Sharp- } \\
\text { bend }\end{array}$} \\
\hline & $\overline{\text { HTs }}$ & $\begin{array}{l}\text { Time, } \\
\text { hrs* }\end{array}$ & $\begin{array}{l}\text { Temp, } \\
\mathrm{C}\end{array}$ & & & \\
\hline$\overline{4338}$ & 3 & 80 & 420 & $\mathrm{C}-\mathrm{B}$ & 746 & pass \\
\hline 4531 & 3 & 40 & 375 & C-A & 749 & pass \\
\hline 4538 & 3 & 80 & 420 & C-A & 760 & fail \\
\hline 6038 & 3 & 80 & 420 & B-5-2 & 764 & fail \\
\hline 6031 & 3 & 40 & 375 & B-5-2 & 770 & pass \\
\hline 5531 & 3 & 40 & 375 & A6-2 & 771 & pass \\
\hline 4541 & 4 & 40 & 375 & C-A & 775 & pass \\
\hline 6131 & 3 & 40 & 375 & B-6-2 & 776 & pass \\
\hline 6138 & 3 & 80 & 420 & B-6-2 & 776 & fail \\
\hline 4331 & 3 & 40 & 375 & C-A & 778 & pass \\
\hline 6041 & 4 & 40 & 375 & B-5-2 & 780 & pass \\
\hline 5441 & 4 & 40 & 375 & A5-2 & 788 & pass \\
\hline 5541 & 4 & 40 & 375 & A6-2 & 789 & pass \\
\hline 6141 & 4 & 40 & 375 & B-6-2 & 793 & pass \\
\hline 5731 & 3 & 40 & 375 & A-8-2 & 793 & pass \\
\hline 4341 & 4 & 40 & 375 & C-B & 794 & pass \\
\hline 5438 & 3 & 80 & 420 & A-5-2 & 794 & fail \\
\hline 5631 & 3 & 40 & 375 & A-7-2 & 797 & pass \\
\hline 5641 & 4 & 40 & 375 & A-7-2 & 805 & pass \\
\hline 5431 & 3 & 40 & 375 & A-5-2 & 805 & pass \\
\hline 5538 & 3 & 80 & 420 & A-6-2 & 805 & fail \\
\hline 5638 & 3 & 80 & 420 & A-7-2 & 811 & fail \\
\hline 5738 & 3 & 80 & 420 & A-8-2 & 821 & fail \\
\hline
\end{tabular}

** First letter is manufacturer identification. 
Table 6. Statistical Evaluation of Springback test results.

\begin{tabular}{lll}
\hline \hline Manufacturer/HT & $\begin{array}{l}\text { Average Springback, } \\
\text { S, degrees }\end{array}$ & $\begin{array}{l}\text { Coefficient of } \\
\text { Variation, } \sigma_{\mathrm{n}-1} / \overline{\mathrm{S}}, \%\end{array}$ \\
\hline B & 767 & 2.2 \\
$\mathrm{C}$ & 777 & 1.2 \\
$\mathrm{~A}$ & 798 & 1.6 \\
375C & 770 & 4.3 \\
420C & 770 & 4.8 \\
3HT at 375C & 764 & 4.6 \\
4HT at 375C & 776 & 3.6 \\
\hline \hline
\end{tabular}

of the billets had nearly identical hardness values $\left(\overline{\mathrm{H}}_{\mathrm{v}}=151,150\right.$ and 149 for B-7, C-1 and C-2 respectively). Both B-5 and B-6 were significantly harder than the rest $\left(\mathrm{H}_{\mathrm{v}}=169\right.$ for $B-5$ and $\bar{H}_{v}=162$ ). The reason for this difference is not clear. All billets used annealed rod except Manufacturer B-6 and B-7, which used partially cold-worked (rotary forged) rod. Billet B-5-2 was one of the worse performing " $B$ " inner billets under our most aggressive heat treatment schedule $(3 \times 288 \mathrm{Ks} / 420 \mathrm{C})$ attaining a peak $\mathrm{J}_{\mathrm{c}}(5 \mathrm{~T})$ of only $2660 \mathrm{~A} / \mathrm{mm}^{2}$ (UW 6038); however, for low temperature heat treatments the performance was similar to B-6-2 (UW6100 series) and B-7-2 (UW6200 series).

\section{H. Barrier Studies}

As indicated by the $n$-value, $J_{c}$, and sausaging data, the $4 \%$ barriers were very successful in reducing intermetallic formation and sausaging to minimal levels. However a new phenomenon was observed at the outer edge of the $\mathrm{Nb}-\mathrm{Ti}$ filaments: Backscatter Electron Images revealed a reduced precipitation size zone adjacent to the $\mathrm{Nb}$ barrier. The width of the zone increased with the aggressiveness of the heat treatment with a maximum thickness of $\sim 2 \mu \mathrm{m}$ with after $80 \mathrm{hr} / 420 \mathrm{C}$ when measured at final HT size. An extensive study([5]) of the diffusion rates across the barrier revealed that $\mathrm{Cu}$ diffusion through the barrier was dominant under these processing conditions. The diffusion of $\mathrm{Cu}$ into the $\mathrm{Nb}-\mathrm{Ti}$ has been indicated by other techniques([6]) and the suggestion is that $\mathrm{Cu}$ is "poisoning" the $\alpha-\mathrm{Ti}$ precipitation process. A detailed examination of the mechanical deformation of the barrier is reported elsewhere([7]).

Table 7. Grain Size Measurements on two alloy supplier " $\mathrm{X}$ " $146 \mathrm{~mm}(5.75 ")$ Billets.

\begin{tabular}{|c|c|c|c|c|c|c|}
\hline \multirow[t]{3}{*}{ Alloy } & \multicolumn{4}{|c|}{ Mean Lineal Intercept, $\mathrm{L}_{3}, \mu \mathrm{m}$} & \multirow{3}{*}{$\begin{array}{l}-\overline{\mathrm{L}}_{\mathrm{z}} \\
\mu \mathrm{m} \\
-\end{array}$} & \multirow{3}{*}{$\begin{array}{l}\sigma_{\mathrm{n}-1} / \mathrm{L}_{3} \\
\%\end{array}$} \\
\hline & \multicolumn{4}{|c|}{$\begin{array}{l}\text { Position relative to center of billet } \\
\text { ( } \mathrm{R}=\text { radius) }\end{array}$} & & \\
\hline & $0-0.25 R$ & $0.25-0.5 R$ & $0.5-0.75 \mathrm{R}$ & $0.75-1 R$ & & \\
\hline $\mathrm{X}-793$ & 86.7 & 97.4 & 78.8 & 62.4 & 81.3 & 9.4 \\
\hline$X-322$ & 93.9 & 104 & 84.7 & 58.7 & 85.3 & 9.2 \\
\hline Mean $\mathrm{L}_{3}$ & 90.3 & 100.7 & 81.8 & 60.6 & 83.3 & 9.3 \\
\hline
\end{tabular}

\section{DISCUSSION}

The Phase II R\&D program has provided us with a comprehensive insight into the current status of accelerator conductor production. The intrinsic nature of the $4 \% \mathrm{Nb}$ diffusion barrier Phase II R\&D conductor also allows us to make specific conclusions about the microstructural contributions towards the performance of the strand.

\section{A. Microstructure and Current Density}

The key result of this study has been the identification of the slow rate of precipitate production in these composites and the resultant disappointing critical current densities. The relationship between volume $\% \alpha$-Ti and $J_{c}$ has been shown to be essentially the same for an ideal monofilament, the Phase II R\&D Inner strand and the UW-61 stacks of SSC monofilament. Thus the focus for future improvement of these conductors must be on the factors that are limiting the volume of $\alpha$-Ti precipitate. Clearly the large additional prestrain available in the UW-61 stacks of the monofilament is not easily transferable to SSC strand manufacture. An important element of the linear relationship between volume $\% \alpha-\mathrm{Ti}$ and $\mathrm{J}_{\mathrm{c}}$ is that the slope increases with final strain([8]). This permits very large $J_{c}$ values by cold drawing laboratory monofilaments where large final drawing strains can be used. It is harder to take full advantage for SSC production where there is a restricted strain space of only 11-12.

The amount of cold work that can be maintained through extrusion should have a major impact on efficient use of available strain space but has yet to be extensively studied. The work of Parrell et al 2 provides a first view of this.

The slope in the $J_{c}$ vs $B$ curve has been shown to be primarily related to precipitate size; however, the consistent difference between the precipitate diameter and slope relationship

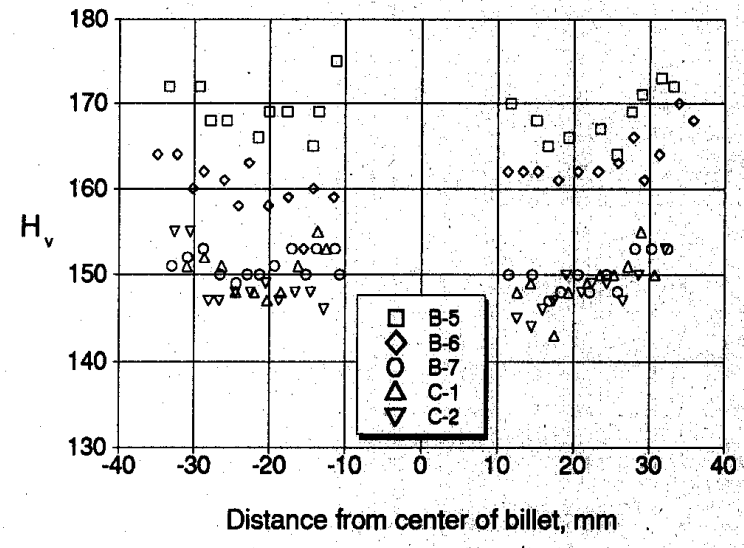

Figure 10 Hardness of $\mathrm{Nb}-\mathrm{Ti}$ filaments with respect to distance from center of billet for $76 \mathrm{~mm}\left(3^{t}\right)$ post extrusion billets from two manufacturers. 
for the UW-61 stack material and the SSC inner strand suggests that there is an additional mechanism and that a closer look at the precipitate size with respect to size distribution is required.

\section{B. Manufacturing Variables}

By processing both monofilament and multifilamentary material from a variety of sources under controlled and identical conditions, we were able to isolate differences in the behavior in the material from each manufacturer.

The uniformity of the Nb-Ti filament hardness across the individual post-extrusion billet slices indicates that the extrusion process produced uniform heat and deformation across the billet. The differences between the hardness levels of different billets (e.g. in the Manufacturer B case) suggest small differences in the extrusion parameters. Further work is necessary in order to ascertain the impact of this hardness difference on subsequent processing.

With the exception of the billets manufactured using the tree-ringed " $\mathrm{Y}$ " alloy, the $\mathrm{J} / \mathrm{B}$ slopes were very consistent $(\sim \pm 1 \%)$ for a given heat treatment schedule applied to composites from any of the manufacturers. This suggests that the precipitation behavior (at least in terms of precipitate size) is very similar for all these composites (note that in these experiments, except for the three billets made from supply " $Y$ " alloy) all the $\mathrm{Nb}$-Ti originated at supply " $\mathrm{X}$ ".

Notable differences in behavior were observed in the Springback test. The average springback for the Manufacturer A strand was 3\% $\left(\sigma_{n-1}=1.6 \%\right)$ higher than the next highest. The spread in values for individual manufacturers $\left(\sigma_{n-1}=1.2-2.8 \%\right)$ was less than when the effects of different heat treatments were monitored $\left(\sigma_{n-1}=3.6-4.8 \%\right)$.

Additional performance over standard industrial practice can be obtained by the use of additional heat treatments at short strain intervals to boost the amount of precipitate([9]). In Table 8 we compare the performance of several of our strands fabricated from billet C-B with the strand supplied by Manufacturer $C$ : Several of the strands performed at or close to 3000 $\mathrm{Amm}^{-2}(5 \mathrm{~T}, 4.2 \mathrm{~K})$ and only two 5-6 heat treatment composites failed to reach SSC strand specification.

\section{CONCLUSIONS}

1. The $4 \% \mathrm{Nb}$ barriers applied to the Phase II R\&D Inner Strand were entirely successful at inhibiting the formation of brittle intermetallic at the Cu-superconductor interface. However a region of reduced precipitate size was observed at the outer edge of the Nb-Ti filaments. The depth of the reduced size zone increased with the aggression of heat

Table 8. Critical Current Results for UW Heat Treated Manufacturer C-B Billet.

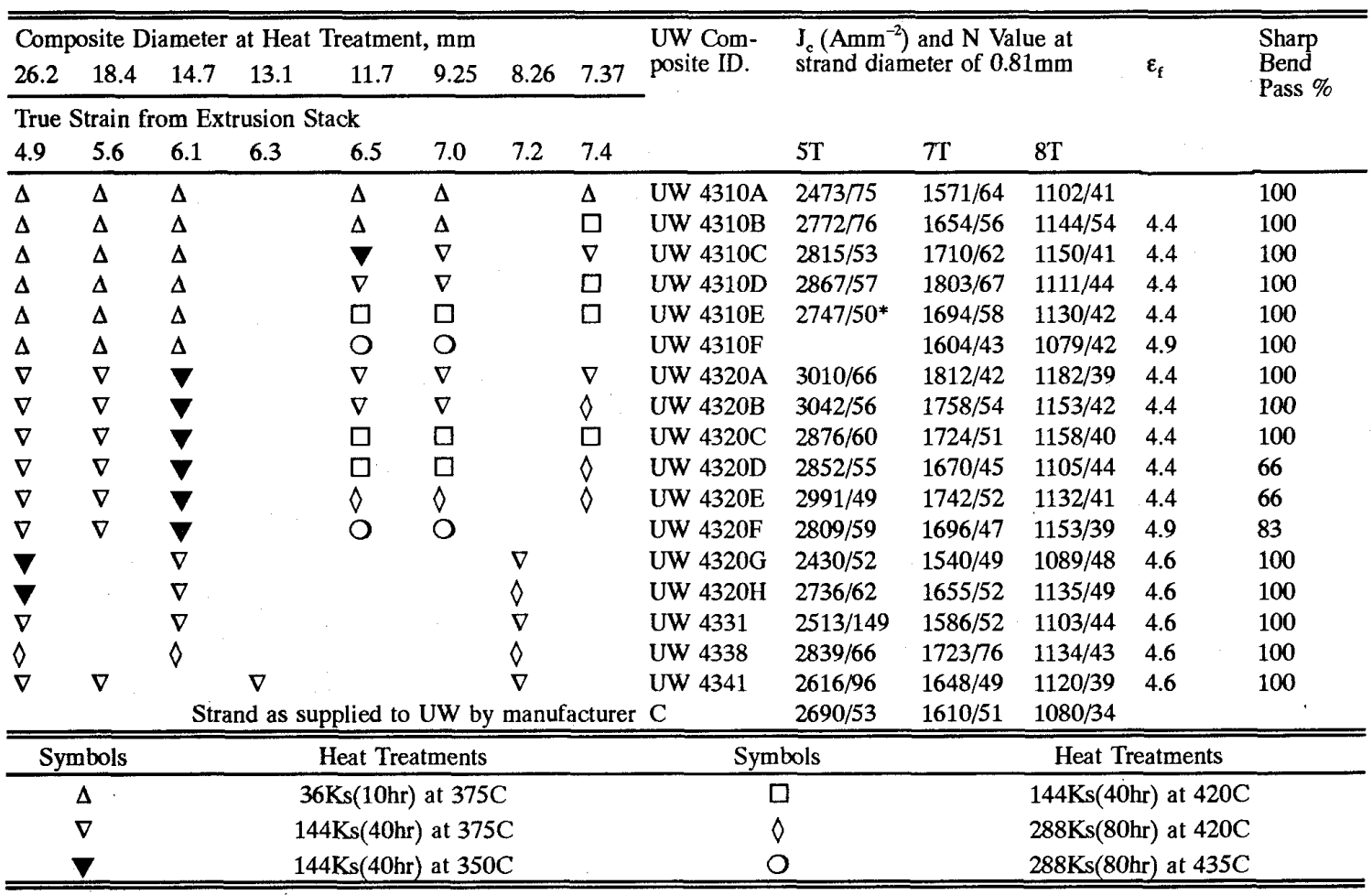

$*=0.75 \mathrm{~mm}$ diameter, $\varepsilon_{\mathrm{f}}=4.6$ 
treatment.

2. The elimination of the formation of brittle intermetallic through the use of the $4 \% \mathrm{Nb}$ barrier resulted in a reduced level of filament sausaging that increased linearly with total strain but was unaffected by heat treatment.

3. The removal of the extrinsic sausaging variable reveals the intrinsic behavior of the $\mathrm{Nb}-\mathrm{Ti}$. A linear relationship between increasing volume $\% \alpha$-Ti and $\mathrm{J}_{\mathrm{c}}$ was exhibited that is the same as that previously found for our laboratory scale monofilaments.

4. The amount of precipitate produced in the SSC strand is significantly (20-30\%) lower than identically heat treated laboratory-scale composites fabricated from SSC monofilament but without the extrusion step or intermediate anneals.

5. The reduced levels of precipitate in the SSC composites produced lower $J_{c}$ values than expected $\left(300-400 \mathrm{~A} / \mathrm{mm}^{2}\right.$ less than equivalent UW-61 stacks). However, $J_{c}$ could be improved by increasing the number of heat treatments, the strain space being made available by reducing the strain interval between heat treatments.

6. The J/B slope was found to be primarily dependent on precipitate size. An approximately linear relationship was found between the ratio of the $J_{c}$ values at $5 T$ and $7 T$ and the average precipitate transverse cross-sectional diameter but there was an offset between the SSC strand data and the UW-61 stacks, resulting in consistently higher ratios for the UW-61 stacks.

7. The precipitate size and thus the $J_{d} / B$ slope was determined primarily by the temperature of heat treatment. Consistent differences between the ratios produced by different manufacturers suggest that there may be additional manufacturing variables that influence either the precipitate size distribution or the relationship between $\mathrm{J}_{\delta} / \mathrm{B}$ and the precipitate diameter.

8. The hardness of the $\mathrm{Nb}$ - $\mathrm{Ti}$ filaments after extrusion were found to be uniform across the billet, indicating homogeneous processing of the billet through extrusion. Hardness levels, however, were found to vary in some cases from billet to billet, suggesting that the extrusion parameters differed slightly in each case. No relationship was found between the initial monofilament condition (annealed compared with partially cold worked) and the hardness after extrusion.

9. The degree of Spring-back and susceptibility to the sharpbend test were found to be manufacturer-dependent.

\section{ACKNOWLEDGEMENTS}

We are grateful to staff at IGC, OST, Supercon, LBL, SSCL, and TWCA for the supply of materials. Wire fabrication was supervised by Bill Starch and Jim McKinnell (now at TWCA) with much assistance by Jon Ponty, Craig Christopherson, Jeff Parrell, Robert Heussner and Douglas Slauson. Yvonne High and Kenneth Faase provided detailed metallographic analysis while Alex Squitieri, Jim McKinnell, Orrin Lokken and Craig Christopherson conducted critical current characterizations. Special thanks are due to R.M. Scanlan (LBL) for his discussions and support throughout the whole procurement and evaluation process. The whole SSC conductor R\&D exercise benefitted enormously from the interest and stimulus provided by Maury Tigner (formerly SSC Central Design Group, now Cornell University).

\section{REFERENCES}

1. Y. E. High, P. J. Lee, J. C. McKinnell and D. C Larbalestier, "Quantitative analysis of sausaging in $\mathrm{Nb}$ barrier clad filaments of $\mathrm{Nb}-46.5 \mathrm{wt} . \% \mathrm{Ti}$ as a function of filament diameter and heat treatment," Adv. Cryo. Eng., vol. 38b, pp. 647-652, 1992

2. J.A. Parrell, P.J. Lee, and D.C. Larbalestier, "Cold work loss during the extrusion of SSC Phase II R\&D composites as measured by microhardness", paper LOD 4 presented at the Applied Superconductivity Conference, Chicago, IL, August 1992.

3. J. C. McKinnell, P. J. Lee, K. Faase, Y. High, A. Squitieri, W. Starch, and D. C. Larbalestier, "Interim report on the properties of phase II SSC superconducting composites, internal report SMRG 107, Applied Superconductivity Center, University of Wisconsin-Madison," 1990.

4. The supply "Y" alloy exhibited strong inhomogeneity "treerings" but did not show significant freckling and would have been difficult to exclude under current alloy homogeneity specifications. This prompted the Conductor Advisory Committee in January 1991 to design a Flash Radiograph standard to allow a more accurate comparison of alloys. The standard was fabricated at the UW and has been distributed to all SSC alloy manufacturers.

5. K. J. Faase, P. J. Lee, J. C. McKinnell and D. C. Larbalestier, "Diffusional reaction rates through the $\mathrm{Nb}$ wrap in SSC multifilamentary wire composites," Adv. Cryo. Eng., vol. 38, pp. 723-730, 1992.

6. J. Moreland, J. W. Ekin, and L. F. Goodrich, "Electron tunneling into superconducting filaments: depth profiling the energy gap of $\mathrm{Nb}$ - Ti filaments from magnet wires," Adv. Cryo. Eng., vol. 32, pp. 1101-1108, 1986.

7. R.W. Heussner, P.J. Lee, and D.C. Larbalestier, "Mechanical deformation of the $\mathrm{Nb}$ diffusion barrier in monofilamentary Nb-Ti wire," paper LOD-10 presented at the Applied Superconductivity Conference, Chicago, II, August 1992.

8. P. J. Lee, M. Melhus and D. C. Larbalestier, " $\mathrm{J}_{\mathrm{c}}$ and $\mathrm{T}_{\mathrm{c}}$ changes produced by $\alpha$-titanium precipitation in optimized $\mathrm{Nb}-47.8 \mathrm{wt} \% \mathrm{Ti}$ alloy," manuscript in preparation, Applied Superconductivity Center, UW-Madison.

9. P. J. Lee, J. C. McKinnell, and D. C. Larbalestier, "Restricted novel heat treatments for obtaining high $\mathrm{J}_{\mathrm{e}}$ in Nb-46.5wt\%Ti," Adv. Cryo. Eng., vol. 36, 287-294, 1990. 